\author{
Pathophysiology \\ of Haemostasis \\ and Thrombosis
}

\title{
Screening for Cancer in Patients with Idiopathic Venous Thromboembolism: The Clinical Practice
}

\author{
J.M.M.B. Otten ${ }^{a}$ S.M. Smorenburg ${ }^{b}$ M.A. de Meij ${ }^{b}$ C.A. van der Schoorb \\ D.P.M. Brandjes ${ }^{c}$ H.R. Büller ${ }^{b}$
}

aDepartment of Internal Medicine and bepartment of Vascular Medicine, Academic Medical Center and

'Department of Internal Medicine, Slotervaart Hospital, Amsterdam, The Netherlands

\section{Key Words}

Thromboembolism, idiopathic venous · Cancer

\begin{abstract}
The reported incidence of concomitant cancer in patients with idiopathic venous thromboembolism (IVTE) varies between 4 and $24 \%$, while the mean incidence of cancer within 3 years thereafter approximates $9 \%$. Baseline investigations of patients with IVTE have been recommended. We evaluated the clinical practice regarding the screening of these patients according to these recommendations in two teaching hospitals. Medical history and physical examination were done reasonably exhaustively, except for investigations of the urogenital tract. Laboratory and imaging investigations were performed incompletely in a substantial proportion of the patients. The clinical evaluation regarding cancer, performed in patients with IVTE, could be improved. The implementation of a protocol should be considered.
\end{abstract}

Copyright $\odot 2002$ S. Karger AG, Basel

\begin{tabular}{ll}
\hline KARGER & @ 2002 S. Karger AG, Basel \\
Fax +416130612 34 & 1424-8832/02/0322-0076\$18.50/0 \\
$\begin{array}{l}\text { E-Mail karger@karger.ch } \\
\text { www.karger.com }\end{array}$ & $\begin{array}{l}\text { Accessible online at: } \\
\text { www.karger.com/journals/pht }\end{array}$
\end{tabular}

\section{Introduction}

Since the initial observation by Trousseau [1] in 1865, the association between cancer and venous thromboembolism (VTE) has been well documented. At the time of diagnosis of a first episode of VTE, approximately $15 \%$ of the patients have an active malignancy [2-4]. In those with idiopathic, i.e. unexplained VTE (IVTE) the reported prevalence of concomitant cancer at the time of VTE varies from 4 to $24 \%$ [3, 5-13]. The difference in these figures can, to a large extent, be explained by the extensiveness of the investigations performed at presentation. The mean incidence of cancer within 3 years after an episode of IVTE in patients older than 40 years, who did not have overt cancer at the time of VTE, is $9 \%$ (reported range 3-26\%). Most of these cancers will become clinically apparent within the first 6 months $[3,5-7,11-18]$. Screening these patients for their still occult cancer could theoretically lead to early intervention and might potentially improve their outcome. Consensus does not exist about the precise diagnostic workup, in particular for the initial clinical evaluation. But data of several recent studies support the concept that the evaluation of patients with IVTE should include a thorough medical history,

\footnotetext{
J.M.M.B. Otten

Department of Internal Medicine, Academic Medical Center

Rm. F4-222, Meibergdreef 9

NL-1105 AZ, Amsterdam (The Netherlands)

Tel. +3120 5669111, Fax +3120 6919743, E-Mail j.m.otten@amc.uva.nl
} 
physical examination, some laboratory investigations, including blood count, liver enzymes, urinalysis, feces for occult blood tests and a chest X-ray [9, 12, 16, 19-21]. Additional testing should be guided by abnormalities detected by these investigations.

Since the report of Prandoni et al. [5] our hospitals advocated a general policy regarding the evaluation of patients with IVTE, and introduced guidelines based on the published recommendations. In the present study we evaluated whether the clinical practice regarding screening for cancer of patients with IVTE was performed according to our guidelines in these two large teaching hospitals.

\section{Methods}

The inpatient registries of the Slotervaart Hospital and Academic Medical Center, both in Amsterdam, The Netherlands, were checked for the records of patients admitted for acute VTE between 1994 and 1998. Charts of patients with a known risk factor for VTE were excluded (for definitions see table 1). At random the files of 50 patients with so-called IVTE were selected in each hospital. The charts contain standardized forms, with questions regarding the medical history and physical examination. Medical students fill in the charts and they are corrected by residents in internal medicine supervised by an internist.

\section{Data Collection}

The records were checked separately by two trained investigators, by means of an a priori designed list of 20 items, and based on the recommendations for early cancer detection $[9,12,16,19-21]$. They specifically looked for indications that the attending physicians had actively searched for signs of cancer. These signs included questions about change in bowel habits, loss of appetite, unexplained weight loss, changes in aspect or pattern of micturition, unusual vaginal blood loss and persistent cough. The investigators also checked whether the physical examination was directed towards the detection of lymphadenopathy and abnormal masses in mammae, abdomen, rectum or genitourinary tract. Furthermore, the performance and results of laboratory and radiological investigations were reviewed. The laboratory investigations were focused on blood count, liver enzymes, protein electrophoresis (to detect multiple myeloma), feces for occult blood tests and urinalysis (to detect microscopic hematuria). Using the checklist the occurrence of the various items was scored for each patients. They were only considered to have been obtained when it was specifically noted in the records. If additional screening procedures were performed, the reason for the procedure was determined. If the routine screening procedures showed abnormalities, the records were checked for additional investigations.

Besides the usual clinical practice we were interested in whether or not the attending physician explicitly mentioned a possible relationship between IVTE and cancer, while performing the investigations. This was assessed by checking both the charts and subsequent correspondence.

The Practice of Cancer Screening in

Patients with Thrombosis
Table 1. Known risk factors for VTE

Known/overt malignancy
Recent surgery (<3 months)
Recent trauma
Pregnancy
Prolonged immobilization
Lupus anticoagulans
Anticardiolipin antibodies
Factor V or factor II mutation
Hyperhomocysteinemia
(Change of) oral contraception
Deficiency of
$\quad$ Antithrombin III
$\quad$ Protein S
$\quad$ Protein C

\section{Results}

The mean age of the 100 study patients was 62 years (range 20-100 years); 55 were women. There were no significant differences between the findings in the two hospitals; hence the results were pooled. The results of the various items scored for the medical history, physical examination, laboratory and radiological investigations are detailed in table 2.

The medical history was obtained reasonably well, but only half of the women had been asked about unusual vaginal blood loss. In most patients the physical examination was nearly complete, with the exception of examination of the breasts, which was only performed in two thirds of the patients, and digital examinations of the rectum and vagina, which was done in 35 and $20 \%$, respectively.

Nearly all patients had a complete blood count done. Testing of liver enzymes (37\%), protein electrophoresis (60\%), feces for occult blood tests (76\%), urinalysis (56\%) as well as chest X-ray (43\%) were not performed in a substantial part of the study population.

In 15 patients the routine investigations revealed an abnormality possibly related to cancer, such as unexplained weight loss, change in bowel habits, suspect rectal, vaginal and breast examination, and anemia. Additional tests were performed in 8 of these patients and led to the diagnosis of cancer in 3 of them. One had metastasized prostate cancer, one had a renal mass of more than $10 \mathrm{~cm}$ and refused further evaluation and the other one had a stage I breast cancer and still is in good condition after adequate surgery. In the other 7 patients an abnormal result in the initial evaluation was not further analyzed. In

Pathophysiol Haemost Thromb 2002;32:76-79 
Table 2. Results of items scored for medical history, physical examination, laboratory and radiological investigations in 100 patients with IVTE

Recorded, \%

\begin{tabular}{ll}
\hline Medical history & \\
Weight loss & 88 \\
Change in bowel habits & 90 \\
Change in micturition habits & 90 \\
Unusual vaginal blood loss & 51 \\
Persistent cough & 91 \\
Loss of appetite & 93 \\
\hline
\end{tabular}

\section{Physical examination}

General impression $\quad 90$

Lymphadenopathy $\quad 88$

Mammae 71

Chest auscultation $\quad 90$

Abdomen 90

Liver/spleen $\quad 90$

Digital rectal examination $\quad 36$

Digital vaginal examination $\quad 22$

\section{Laboratory}

Complete blood count $\quad 94$

Liver enzymes 63

Protein electrophoresis $\quad 40$

Feces occult blood $\quad 24$

Urinalysis 44

Radiology

Chest X-ray

1 patient her mental condition (dementia) was the reason to withhold further tests, while the other 6 patients refused further evaluation because of old age and physical condition. These patients were all lost to follow-up. Although routine evaluation did not show abnormalities, additional testing was performed in 11 patients. The additional tests involved ultrasound of the abdomen in 10 patients, CT abdomen in 5, mammography in 4 and gastroscopy in 1 patients. None of these additional tests revealed signs of malignant disease.

The subjective review of the records revealed 52 cases, in which the attending physician clearly had the relation between IVTE and cancer in mind, while performing the investigations. In 12 records it was not possible to determine whether or not the relation between IVTE and cancer was actively pursued. In the remaining 36 cases there was no indication that the physicians made the association between the IVTE and (occult) cancer.

\section{Discussion}

We evaluated the current practice of screening for the presence of occult cancer in patients with IVTE in two large Dutch teaching hospitals. From a cohort of 654 consecutive patients the charts of 100 patients with IVTE were identified at random. This method, therefore, gives a representative picture of the screening procedure in patients with IVTE admitted in these hospitals during the study period.

The present investigation has some limitations. Its retrospective nature obviously might have influenced our results. On the other hand, a prospective design could have influenced the results as well. Furthermore, we relied on the charts and charts written by physicians are known to be concise. In our hospital, however, medical students completed the standardized charts in cooperation with residents. Therefore, we believe the information needed could be retrieved from the charts.

Our main findings indicate that medical history was taken and physical examination performed reasonably exhaustively. The only exceptions were questions about unusual vaginal blood loss, and examination of mammae, vagina and rectum. Additional laboratory and imaging investigations were not completed as recommended in a substantial part of the patients. The only positive exception was the performance of the complete blood count. Protein electrophoresis, urinalysis and particularly feces occult blood tests were performed in a minority of the patients. The gaps in the medical history and the physical examination might be related to the attitude of the physicians and patients towards investigations of the genital tract.

The lack of awareness of the association between IVTE and cancer is the most likely explanation for the absence of laboratory investigations and chest X-rays. This presumed lack of awareness is supported by the subjective review of the records. In as much as 36 records we could not identify any sign of the physician actively making the association between IVTE and a possible malignancy.

The recommended screening at presentation, also represented in our 20-item checklist, is not based on any study comparing survival benefit of screening with no screening in patients with IVTE. Therefore, no standard protocol exists.

However, a protocol for screening is justified when (1) the disease of interest is serious and common, (2) the natural history of the disease is well understood, (3) the screening tests applied are accurate and reliable and (4) an acceptable treatment is available [22-24]. Cancer is a seri- 
ous disease and common in IVTE patients. Without treatment cancer will ultimately lead to death, the time period depending on the type and the extent of the tumor. The accuracy and reliability of routine evaluation in this setting have to be determined. For several kinds of malignancies treatment is available and could favorably influence outcome, even when the tumor is advanced (such as breast, cervix, ovary, testis and lymphoma). Even though there is no proof that the recommended evaluation has an advantage in terms of survival, there is a general consensus that the routine evaluation should be performed in patients with IVTE, because of the possible early detection of cancer [21]. The procedure mentioned is very simple, cheap and minimally invasive, with no risk for complications.

At present more extensive screening procedures are not recommended for various reasons. Recent studies could not detect a survival benefit in patients with IVTE who underwent extensive screening involving, for example, testing of tumor markers, abdominopelvic ultrasound and computer tomography $[3,6,9,13]$. However, most of these studies were retrospective and/or included too few patients to be able to detect a significant difference. Moreover, the costs of more extensive screening procedures are not negligible when they have to be performed in all patients with IVTE. In $10 \%$ of our population additional procedures were performed for no obvious reason. Most of the additional tests were noninvasive. They did not reveal a malignancy in any of the patients.

Our study shows that the clinical evaluation regarding cancer performed in patients with IVTE in two teaching hospitals in Amsterdam could be improved. One way is to increase the awareness of the relation between IVTE and concomitant cancer and (occult) cancer. Another possibility is to institute the recommendations more formally.

\section{References}

1 Trousseau A: Lectures on Clinical Medicine, Delivered at the Hôpital-Dieu, Paris, ed 3 (translated from the third edition of 1868 by Sir John Rose Cormack). London, The New Sydenham Society, 1872, vol 5, pp 281-332.

2 Carson JL, Kelley MA, Duff A, Weg JG, Fulkerson WJ, Palevsky HI, Schwartz JS, Thompson BT, Popo J Jr, Hobbins TE, Spera MA, Alavi A, Terrin ML: The clinical course of pulmonary embolism. N Engl J Med 1992;326: 1240-1345.

3 Monreal M, Fernandez-Llamazares J, Perandreu J, Urrautia A, Sahuquillo JC, Contel E: Occult cancer in patients with venous thromboembolism: Which patients, which cancers. Thromb Haemost 1997;78:1316-1318.

4 Baron JA, Gridley G, Weiderpass E, Nyrén O, Linet M: Venous thromboembolism and cancer. Lancet 1998;351:1077-1080.

5 Prandoni P, Lensing AW, Buller HR, Cogo A, Prins MH, Cattelan AM, Cuppini S, Noventa F, ten Cate JW: Deep-vein thrombosis and the incidence of subsequent symptomatic cancer. N Engl J Med 1992;327:1128-1133.

6 Monreal M, Lafoz E, Casals M, Injaraja L, Montserrat E, Ma Callejas J, Martorelli A: Occult cancer in patients with venous thrombosis. A systematic approach. Cancer 1991;67:541554.

7 Monreal M, Salvador R, Soriano V, Sabria M: Cancer and deep venous thrombosis. Arch Intern Med 1988;148:485.
8 Achkar A, Laaban JP, Horellou MH, Rabbat A, Conard J, Nataf J, Samama MM, Rochemaure $\mathrm{J}$ : Prospective screening for occult cancer in patients with venous thromboembolism. Thromb Haemost 1997(OC-1564):383 S.

9 Bastounis EA, Karayiannakis AJ, Makri GG, Alexiou D, Papalambros EL: The incidence of occult cancer in patients with deep venous thrombosis: A prospective study. J Intern Med 1996;239:153-156.

10 Rance A, Emmrich J, Guedj C, Fiessinger J-N: Occult cancer in patients with bilateral deepvein thrombosis. Lancet 1997;350:1448-1449.

11 Girolami A, Prandoni P, Zanon E, Bagatella P, Girolami B: Venous thromboses of upper limbs are more frequently associated with occult cancer as compared with those of lower limbs. Blood Coagul Fibrinolysis 1999;10:455-457.

12 Cornuz J, Pearson SD, Creager MA, Cook EF, Goldman L: Importance of findings on the initial evaluation for cancer in patients with symptomatic idiopathic deep venous thrombosis. Ann Intern Med 1996;125:785-793.

13 Sanella NA, O'Connor DJ: 'Idiopathic' deep venous thrombosis: The value of routine abdominal and pelvic computed tomographic scanning. Ann Vasc Surg 1991;5:218-222.

14 Aderka D, Brown A, Zelikovski A, Pinkhas J: Idiopathic deep vein thrombosis in an apparently healthy patient as a premonitory sign of occult cancer. Cancer 1986;57:1846-1849.

15 Rajan R, Levine M, Gent M, Hirsch J, Geerts $\mathrm{W}$, Skingley P, Julian J: The occurrence of subsequent malignancy in patients presenting with deep vein thrombosis: Results from a historical cohort study. Thromb Haemost 1998;79:19_ 22.
16 Gore JM, Appelbaum JS, Greene HL, Dexter L, Dalen JE: Occult cancer in patients with acute pulmonary embolism. Ann Intern Med 1982;96:556-560

17 O'Connor NTJ, Cederholm-Williams SA, Fletcher EW, Allington M, Sharp AA: Significance of idiopathic deep venous thrombosis. Postgrad Med J 1984;60:275-277.

18 Hettiarachchi RJK, Prins MH, Büller HR, Prandoni P, ten Cate JW: Occult malignancy in patients with deep-vein thrombosis. Incidence and risk indicators. Thromb Haemost 1997(OC-1563):383 S

19 Ahmed Z, Mohyuddin Z: Deep vein thrombosis as a predictor of cancer. Angiology 1996;47: 2615.

20 Nordström M, Lindblad B, Anderson H, Bergqvist D, Kjellström T: Deep venous thrombosis and occult malignancy: An epidemiological study. BMJ 1994;308:891-894.

21 Büller HR, ten Cate JW: Primary venous thromboembolism and cancer screening. $\mathrm{N}$ Engl J Med 1998;338:1221-1222.

22 Prins MH: Screening for occult malignant disease in symptomatic idiopathic venous thromboembolism; in The Prevention and Management of Venous Thrombosis. Clinical and Methodological Studies (dissertation), University of Amsterdam, 1993, pp 174-184.

23 Mera SL: Screening for cancer and pre-cancer. Br J Biomed Sci 1995;52:120-141.

24 Wilson JMJ, Junger G: Principles and Practice of Screening for Disease. Geneva, WHO Public Health Paper, 1968, No 34. 